\title{
Efficacy of Locally Administered 1.2\% Rosuvastatin Gel in Patients with Periodontitis: A Randomized Placebo Controlled Clinical Trial
}

\author{
Debopriya Chatterjee ${ }^{1}$ Anjali Kapoor ${ }^{1} \quad$ Sharmistha Vijay ${ }^{1} \quad$ Geetika Sobti $^{2}$ Dheeraj Kara ${ }^{3}$ \\ Jaishree Thanvi²
}

${ }^{1}$ Department of Periodontics, College of Dental Sciences, Rajasthan University of Health Sciences, Jaipur, Rajasthan, India

${ }^{2}$ Department of Oral Medicine, Radiology and Diagnosis, College of Dental Sciences, Rajasthan University of Health Sciences, Jaipur, Rajasthan, India

${ }^{3}$ Department of Public Health, YMT Dental College, Navi Mumbai, Maharashtra, India

Address for correspondence Debopriya Chatterjee, MDS. Department of Periodontics, Rajasthan University of Health Sciences College of Dental Sciences, Jaipur, Rajasthan, India (e-mail: banerjee.debo@gmail.com).

Eur J Dent 2019;13:29-35

\begin{abstract}
Objective Periodontitis initiation and progression are a result of host immune inflammatory response to oral pathogens. Several pharmacological agents are being delivered locally, to improve periodontal health. Hence, the present randomized placebo controlled clinical trial is designed to check the clinical and antimicrobial efficacy of locally delivered $1.2 \%$ rosuvastatin (RSV) in intrabony defects (IBD) in periodontitis patients.

Materials and Methods One-hundred patients were randomly allotted into two treatment groups: group A received 1. 2\% RSV gel, scaling and root debridement and group $B$ received placebo gel, scaling and root debridement. Clinical parameters, including modified sulcus bleeding index (mSBI), probing depth (PD), clinical attachment level (CAL), and plaque index (PI), were recorded at baseline before phase 1 and after 6 months. Radiographic assessment of IBD was done by cone beam computed tomography at baseline and after 6 months. Anaerobic colony count was done at baseline and after 180 days.

Results On intragroup comparison, there is a significant improvement in periodontal parameters in both the groups. On intergroup comparison, there is significant gain in CAL in group $A$ than group $B(p=0.04)$. There is significant decrease in PD in group $A$, compared to group $B$. There is significant bone fill in group $A(p=0.034)$, compared to

Keywords

- bone loss

- inflammation

- periodontitis

- statins group $B$. With respect to $\mathrm{mSBI}, \mathrm{PI}$, and anaerobic colony count, there is no significant difference between the two groups after 6 months. No adverse effect was noticed in any subjects.

Conclusion The author concludes that $1.2 \%$ RSV gel when delivered locally into IBD improved periodontal clinical parameters such as PD and CAL and showed significant bone fill.
\end{abstract}

\section{Introduction}

Periodontitis is an infectious disease, initiated by oral microbial biofilm that results in inflammation in the supporting tissue of teeth, leading to progressive clinical attachment and bone loss, and further creating intrabony defects (IBD). ${ }^{1}$ The inflammatory condition is due to imbalance in host immune response against microbial challenge. ${ }^{2}$ 
Periodontitis is a site-specific disease. It is due to local bacterial infection. The microflora found in periodontitis is complex and composed of anaerobic and Gram-negative bacteria. ${ }^{3}$ Progression of the disease is the net effect of immune response and inflammatory disease, rather than mere presence of microflora. ${ }^{4}$

The primary objective of treatment of periodontitis is to halt the progression of disease and resolve inflammation. ${ }^{5}$ Among the various treatment modalities, scaling and root debridement remains the gold standard nonsurgical management of chronic periodontitis. ${ }^{6}$ Local delivery of pharmacological agents, especially in local periodontal defect area, has gained interest due to site-specific nature of periodontal infection. ${ }^{7}$ To complement mechanical debridement, local delivery of various pharmacologic agents using sustained/controlled release vehicle is directly administered into periodontal pocket, targeting specific microorganism, and even to modulate host inflammatory response. ${ }^{8}$

Statins are lipid-lowering drugs. They are competitive inhibitor of 3-hydroxy-3-methylglutaryl coenzyme A reductase, which is the key enzyme in cholesterol biosynthesis. Statins are considered as main drug in treating cardiovascular diseases. ${ }^{9}$ Statins exhibit broad-spectrum pleiotropic effects. The reduction in mevalonate pathway by statins is responsible for numerous pleiotropic effect of these drugs. ${ }^{10}$

The potential pleiotropic effects include cholesterolindependent anti-inflammatory, modulation, of vascular response, ${ }^{11}$ microvascular reperfusion, ${ }^{12}$ and antimicrobial effect. ${ }^{13}$ They possess intrinsic antioxidant properties. ${ }^{11}$ Both in vitro and in vivo animal models, statin stimulates bone formation, associated with increased expression of the BMP-2 gene in bone cells. Increased BMP-2 expression causes osteoblast differentiation. They inhibit osteoclast differentiation. ${ }^{14}$

Rosuvastatin (RSV) is synthetic sulfur containing hydrophilic statin. RSV unlike other lipophilic drug is actively transported in osteoblastic cell through solute carrier. RSV induces BMP 2 gene expression, secretion, and increases alkaline phosphatase activity, demonstrating osteoblastic differentiation. ${ }^{14,15}$

Adult patients $\geq 30$ years old with periodontitis showed improvement in their periodontal status on simultaneous administration of either systemic or locally delivered statins in adjunct to nonsurgical therapy. ${ }^{16}$ Another systematic review with meta-analyses concluded that statin along with scaling and root debridement promotes significant periodontal parameter improvement. ${ }^{17}$ Due to pleiotropic effects of statins, it can evolve as a novel economic, host modulating, and bone anabolic agent in the treatment of periodontitis. Based on the available data, the present randomized study is designed to evaluate the clinical and antimicrobial efficacy of locally administered $1.2 \%$ RSV gel adjunct to scaling and root debridement in periodontitis patients compared to placebo gel.

\section{Materials and Methods}

The present study was single center, 6-month follow-up, double-blinded randomized clinical placebo-controlled trial. A total of 145 patients with periodontitis were screened at outpatient section of the Department of Periodontics, Jaipur, Rajasthan University Health Sciences-College of Dental Science (RUHS-CODS) (-Fig. 1). One-hundred patients (47 males and 53 females, aged between 30 and 60 years) were selected based on the inclusion criteria. The study period was from February 2017 to March 2018. The study was approved by Rajasthan University Health Sciences-College of Medical Science Ethics Committee, Jaipur. The study was funded by Rajasthan University Health Sciences.

\section{Selection Criteria}

Patients, who were systemically healthy and had periodontitis with clinical attachment level $(C A L) \geq 3 \mathrm{~mm}$, probing depth (PD) $\geq 4 \mathrm{~mm}$, and vertical bone loss $\geq 3 \mathrm{~mm}$ measured on cone beam computed tomography (CBCT), were included in this study. Patients with $\geq 20$ teeth and no history of any kind of periodontal therapy and antibiotic therapy in the last 6 months were selected for the study. Patients on statin therapy or under any kind of medication, immunocompromised, use of tobacco in any form, pregnant and lactating female were excluded from the study. All volunteers signed the informed consent.

\section{Randomization and Clinical Procedures}

On the basis of power calculation (power of study $80 \%$ and $p \leq 0.05 \%), 100$ patients were randomly allotted in (computer-generated randomization) into two treatment group. Group A received scaling and root debridement and $1.2 \%$ RSV gel $(1.2 \mathrm{mg} / 0.1 \mathrm{~mL})$ locally delivered and group $B$ received scaling and root debridement and placebo gel. At baseline, scaling and root debridement was done by a blinded investigator. Investigator was a trained dentist. Scaling and root debridement involves the removal of supra and subgingival deposits. ${ }^{18}$ Volunteers in both the groups were instructed similar oral hygiene instruction. Patients were also unaware of the allocation of RSV gel or placebo gel. Delivery of RSV gel or placebo gel into the defect site was done by another masked investigator. Allocation concealment was kept by means of coded identical container, as both examiner and dentist responsible for the periodontal therapy were not involved in that process.

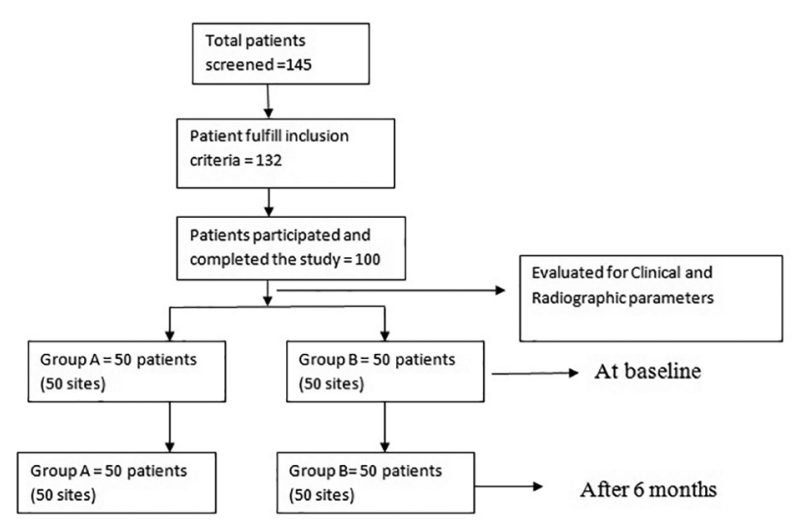

Fig. 1 Study flowchart 1. 


\section{Clinical Parameters}

Clinical parameters included site-specific-plaque index (PI), ${ }^{19}$ $\mathrm{PD}, \mathrm{CAL}$, modified sulcus bleeding index $(\mathrm{mSBI})^{20}$ of the target tooth were recorded at baseline and after 6 months. For standardization, a custom-made acrylic stent and UNC-15 probe were used. CAL was measured from apical point of stent to the base of the pocket minus distance between apical point of stent to cementoenamel junction (CEJ). PD was measured from gingival margin to base of the pocket. The clinical parameter was measured by a trained and calibrated investigator.

\section{Subgingival Plaque Sampling and Microbial Culture}

Subgingival plaque samples were randomly collected from 32 patients ( 32 sites) from each group ( - Fig. 2). Subgingival microbial plaque sample was collected from the same site as of local drug delivery area at baseline and after 180 days with the help of sterile Gracey curette. The site of collection was isolated with cotton roll and supragingival plaque was gently removed. The curette was inserted deep into the pocket without applying any pressure on the tooth surface, to avoid dislocation of subgingival plaque. As soon as the curette reached the apical part of the pocket, subgingival sample was collected with single vertical stroke. For transport of the sample, the working end of the curette was swiped with sterile swab stick. The swab stick was immediately transferred to thioglycolate broth (anaerobic transport media). The samples were processed for anaerobic growth within 4 hours. Measurement was done in colony-forming unit/mL (CFU/mL).

\section{Radiographic Evaluation of Intrabony Defects}

IBD were measured using CBCT. The patients who fulfilled the inclusion criteria underwent CBCT examination with a field of volume $10 \mathrm{~cm} \times 10 \mathrm{~cm}$. CBCT analysis was done by a blinded trained investigator, who was not involved in another evaluation or clinical procedure. The vertical defect was measured in sagittal section from a reference point, that is, CEJ to base of the defect. The analysis was done at baseline and after 6 months (-Figs. 3 and $\mathbf{4}$ ).

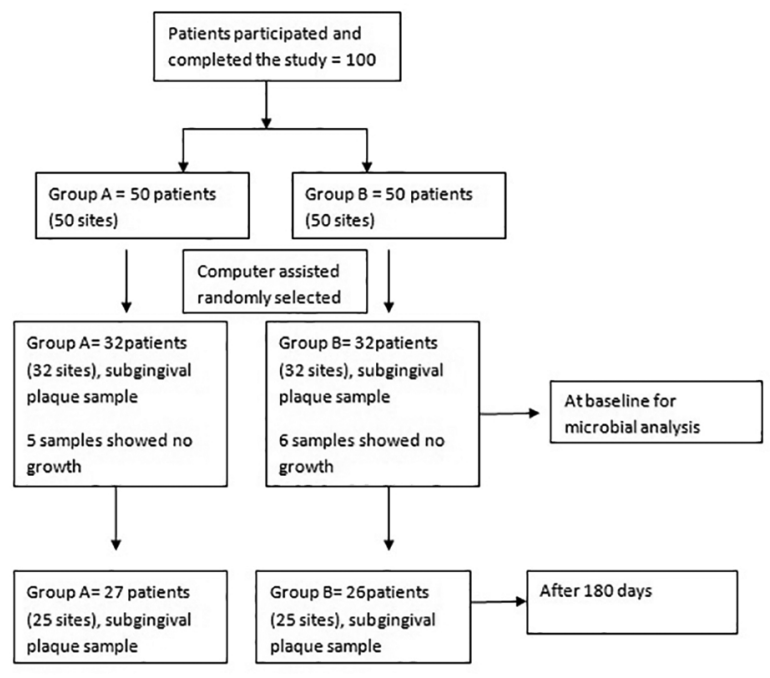

Fig. 2 Study flowchart 2.

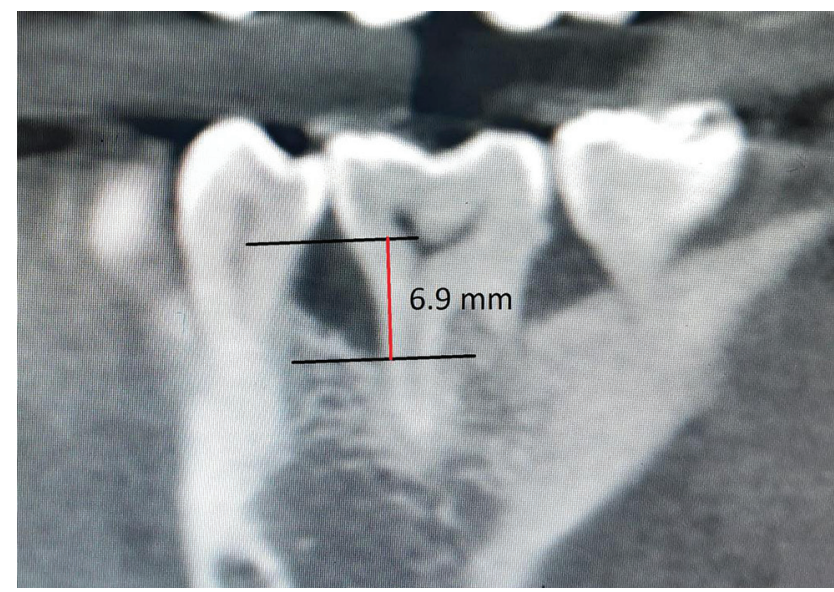

Fig. 3 Sagittal section preoperative image of angular defect, measured from cementoenamel junction to base of defect.

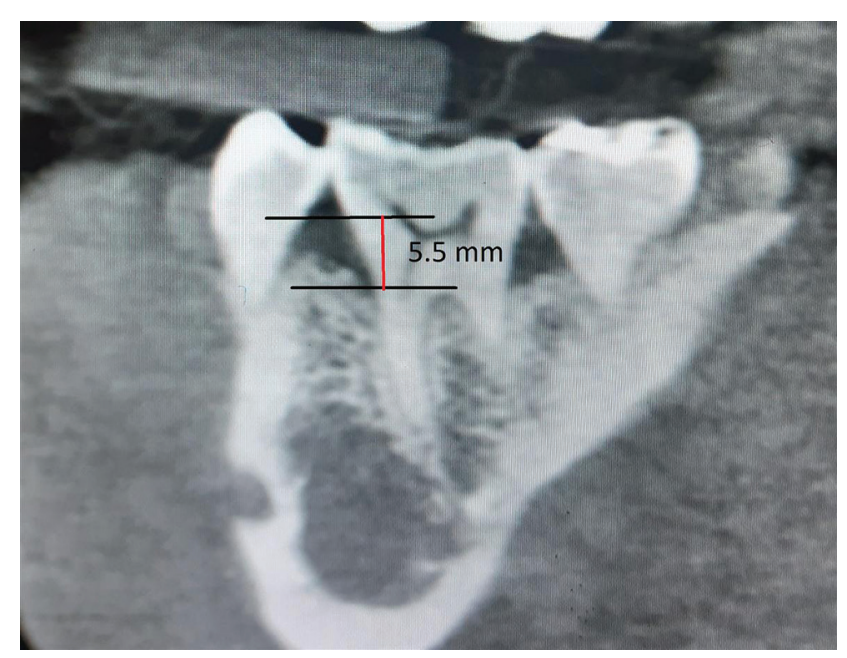

Fig. 4 Sagittal section postoperative image of the angular defect, measured from cementoenamel to the base of defect.

\section{Formulation and Delivery of $1.2 \%$ Rosuvastatin and Placebo Gel}

Methylcellulose was used as vehicle for sustained release of drug. ${ }^{21} 2.0 \% \mathrm{w} / \mathrm{v}$ methylcellulose was dissolved in tripledistilled water to produce methylcellulose gel, which was used as the RSV carrier after it cooled down. Sodium methylparaben and sodium propylparaben were added to methylcellulose gel in the concentration of 0.1 and $0.02 \%$, respectively, as preservative. RSV was then added to the methylcellulose gel to generate suspension of the desired concentration, $1.2 \mathrm{mg} / 0.1 \mathrm{~mL}$. The suspension was sonicated and stored at $4^{\circ} \mathrm{C}$ for future use. Placebo gel was methylcellulose without any active ingredient.

A volume of $0.1 \mathrm{~mL}$ RSV gel $(1.2 \mathrm{mg} / 0.1 \mathrm{~mL})$ was injected into the periodontal pocket through a syringe. After placement of gel in both the groups, patients were instructed not to chew and to gently clean the treated area. Patients in both groups were given same oral hygiene instructions and were made to recall after 6 months. There was no adverse effect reported to RSV gel. 


\section{Primary and Secondary Outcome}

The primary outcome of the study was bone fill. The secondary outcome was improvement in the clinical parameters such as mSBI, PI, PD, CAL, and reduction in anaerobic CFU.

\section{Statistics}

Data obtained was compiled on an MS Office Excel Sheet (v 2010, Redmond, Washington, United States) and was subjected to statistical analysis using Statistical package for social sciences (SPSS v 21.0, IBM, Armonk, New York, United States). Normality of data was checked using KolmogorovSmirnov test and was found that data followed a normal distribution. Intergroup comparison of numerical variables was done using $t$-test. In addition, intragroup comparison was done using paired $t$-test. Comparison of frequencies of colony patterns in both the groups and intragroup has been done using chi-squared test. $p<0.05$ was considered to be statistically significant, keeping $\alpha$ error at $5 \%$, and $\beta$ error at $20 \%$, thus giving a power to the study as $80 \%$.

\section{Results}

A total of 145 patients were screened, out of which 100 patients fulfilled the inclusion criteria and completed the study. There were 50 participants in each group.

On intergroup comparison at baseline, there was no statistically significant difference between clinical periodontal, radiographic, and anaerobic colony count parameter. CAL parameter at baseline of both the groups was similar $(p=0.454)$. There was statistically significant gain in CAL in group A compared to group B after 6 months ( $p=0.044)$. The mean PD of both the groups was similar at baseline $(p=0.888)$. There was statistically significant decrease in mean PD in group A compared to group B after 6 months $(p=0.00)$. IBD was similar in both the groups at baseline $(p=0.394)$. On intergroup comparison, there was statistically significant decrease in mean IBD in group A (6.5 $\pm 1.71-5.23$ $\pm 1.46)$, compared to group B (6.22 $\pm 1.50-6.02 \pm 0.299)$ from baseline to 6 months ( $p=0.034$; - Tables 1 and 2 ). On intragroup comparison in group $\mathrm{A}$, all the periodontal clinical parameter and radiographic parameters showed significant improvement after 6 months. Within group B, except for radiographic parameter, all clinical parameters showed significant improvement after 6 months ( - Tables 3 and 4 ).

At baseline, mSBI scores were similar in both the groups, with $p=0.968$. There was statistically no significant difference in mSBI scores in both the groups after 6 months, with $p=0.692$. The mean PI also showed no significant difference after 6 months. The mean values of anaerobes $\mathrm{CFU} / \mathrm{mL}$ of the two groups were similar at baseline, and there was no significant difference after 180 days in the mean value of anaerobes $\mathrm{CFU} / \mathrm{mL}$ between two groups (-Table 5 ). None of the patients showed any kind of side effect to RSV and placebo gel.

\section{Discussion}

The present study evaluates the clinical and antimicrobial efficacy of RSV. In periodontitis, the balance between periodontal
Table 1 Intergroup probing depth, clinical attachment level, intrabony defect, plaque index, modified sulcus bleeding index (mean \pm 6 standard deviation) at baseline

\begin{tabular}{|c|c|c|c|}
\hline $\begin{array}{l}\text { Parameters } \\
\text { (at baseline) }\end{array}$ & $n$ & Mean & $p$-Value \\
\hline \multicolumn{4}{|l|}{ CAL } \\
\hline Group A & 50 & $7.32 \pm 1.51$ & \multirow[t]{2}{*}{0.454} \\
\hline Group B & 50 & $7.10 \pm 1.40$ & \\
\hline \multicolumn{4}{|l|}{ PD } \\
\hline Group A & 50 & $6.29 \pm 1.17$ & \multirow[t]{2}{*}{0.88} \\
\hline Group B & 50 & $6.25 \pm 1.59$ & \\
\hline \multicolumn{4}{|l|}{$\mathrm{mSBI}$} \\
\hline Group A & 50 & $3.83 \pm 0.73$ & \multirow[t]{2}{*}{0.968} \\
\hline Group B & 50 & $3.82 \pm 0.75$ & \\
\hline \multicolumn{4}{|l|}{$\mathrm{PI}$} \\
\hline Group A & 50 & $1.83 \pm 0.58$ & \multirow[t]{2}{*}{0.213} \\
\hline Group B & 50 & $1.96 \pm 0.47$ & \\
\hline \multicolumn{4}{|l|}{ IBD } \\
\hline Group A & 50 & $6.50 \pm 1.71$ & \multirow[t]{2}{*}{0.394} \\
\hline Group B & 50 & $6.22 \pm 1.50$ & \\
\hline
\end{tabular}

Abbreviations: CAL, clinical attachment level; IBD, intrabony defect; mSBI, modified sulcus bleeding index; PD, probing depth; PI, plaque index.

Table 2 Intergroup probing depth, clinical attachment level, intrabony defect, plaque index, modified sulcus bleeding index (mean \pm 6 standard deviation) after 6 months

\begin{tabular}{|c|c|c|c|}
\hline $\begin{array}{l}\text { Parameters (after } \\
6 \text { months) }\end{array}$ & $n$ & Mean & $p$-Value \\
\hline \multicolumn{4}{|l|}{ CAL } \\
\hline Group A & 50 & $4.18 \pm 0.96$ & \multirow[t]{2}{*}{$0.044^{*}$} \\
\hline Group B & 50 & $4.5 \pm 0.90$ & \\
\hline \multicolumn{4}{|l|}{ PD } \\
\hline Group A & 50 & $3.44 \pm 0.73$ & \multirow[t]{2}{*}{$0.000 * *$} \\
\hline Group B & 50 & $4.02 \pm 0.65$ & \\
\hline \multicolumn{4}{|l|}{$\mathrm{mSBI}$} \\
\hline Group A & 50 & $1.54 \pm 0.62$ & \multirow[t]{2}{*}{0.692} \\
\hline Group B & 50 & $1.59 \pm 0.64$ & \\
\hline \multicolumn{4}{|l|}{$\mathrm{PI}$} \\
\hline Group A & 50 & $0.994 \pm 0.47$ & \multirow[t]{2}{*}{0.900} \\
\hline Group B & 50 & $0.98 \pm 0.47$ & \\
\hline \multicolumn{4}{|l|}{ IBD } \\
\hline Group A & 50 & $5.23 \pm 1.46$ & \multirow[t]{2}{*}{$0.034^{*}$} \\
\hline Group B & 50 & $6.02 \pm 0.299$ & \\
\hline
\end{tabular}

Abbreviations: CAL, clinical attachment level; IBD, intrabony defect; mSBI, modified sulcus bleeding index; PD, probing depth; PI, plaque index.

breakdown (disease) and periodontal stability (health) is tipped toward disease by risk factors and by overactivity or underactivity of host immune inflammatory response. ${ }^{22}$ 
Table 3 Intragroup comparison of PD, CAL, IBD, PI, mSBI of group $A$

\begin{tabular}{|l|l|l|l|l|}
\hline & & Mean & $n$ & $\begin{array}{l}\text { p-Value of } \\
\text { paired } t \text { test }\end{array}$ \\
\hline \multirow{2}{*}{ Pair 1 } & IBD B & $6.50 \pm 1.71$ & 50 & $0.000^{* *}$ \\
\cline { 2 - 5 } & IBD 6m & $5.23 \pm 1.46$ & 50 & \\
\hline \multirow{2}{*}{ Pair 2 } & CAL B & $7.32 \pm 1.5$ & 50 & $0.000^{* *}$ \\
\cline { 2 - 5 } & CAL 6m & $4.180 \pm 0.96$ & 50 & \\
\hline \multirow{2}{*}{ Pair 3 } & Probing b & $6.290 \pm 1.17$ & 50 & $0.000^{* *}$ \\
\cline { 2 - 5 } & Probing 6m & $3.44 \pm 0.73$ & 50 & \\
\hline \multirow{2}{*}{ Pair 4 } & Bleeding b & $3.83 \pm 0.73$ & 50 & $0.000^{* *}$ \\
\cline { 2 - 5 } & Bleeding 6m & $1.546 \pm 0.62$ & 50 & \\
\hline \multirow{2}{*}{ Pair 5 } & Plaque b & $1.83 \pm 0.58$ & 50 & $0.000^{* *}$ \\
\cline { 2 - 5 } & Plaque 6m & $0.99 \pm 0.58$ & 50 & \\
\hline
\end{tabular}

Abbreviations: CAL, clinical attachment level; IBD, intrabony defect; mSBI, modified sulcus bleeding index; PD, probing depth; PI, plaque index.

Table 4 Intragroup comparison of PD, CAL, IBD, PI, mSBI of group B

\begin{tabular}{|l|l|l|l|l|}
\hline \multirow{2}{*}{ Pair 1 } & Mean & $n$ & $\begin{array}{l}p \text {-Value of } \\
\text { paired } t \text { test }\end{array}$ \\
\cline { 2 - 5 } & IBD B & $6.22 \pm 1.5$ & 50 & $0.341 \#$ \\
\hline \multirow{2}{*}{ Pair 2 } & CAL B & $7.10 \pm 1.4$ & 50 & $0.000^{* *}$ \\
\cline { 2 - 5 } & CAL 6m & $4.0 \pm 0.94$ & 50 & \\
\hline \multirow{2}{*}{ Pair 3 } & Probing b & $6.25 \pm 0.59$ & 50 & $0.000^{* *}$ \\
\cline { 2 - 5 } & Probing 6m & $4.02 \pm 0.63$ & 50 & \\
\hline \multirow{2}{*}{ Pair 4 } & Bleeding b & $3.83 \pm 0.75$ & 50 & $0.000^{* *}$ \\
\cline { 2 - 5 } & Bleeding 6m & $1.59 \pm 0.64$ & 50 & \\
\hline \multirow{2}{*}{ Pair 5 } & Plaque b & $1.96 \pm 0.47$ & 50 & $0.000^{* *}$ \\
\cline { 2 - 5 } & Plaque 6m & $0.98 \pm 0.47$ & 50 & \\
\hline
\end{tabular}

Abbreviations: CAL, clinical attachment level; IBD, intrabony defect; $\mathrm{mSBI}$, modified sulcus bleeding index; PD, probing depth; PI, plaque index.

Table 5 Intergroups anaerobic CFU/mL after 6 months

\begin{tabular}{|l|l|l|l|l|l|}
\hline \multirow{2}{*}{ Frequency } & \multicolumn{3}{|c|}{$\begin{array}{c}\text { 6 months anaerobic } \\
\text { CFU/mL }\end{array}$} & Total & p-Value \\
\cline { 2 - 5 } & No growth & $10^{2}$ & $10^{3}$ & & \\
\hline Groups A & 16 & 6 & 5 & 27 & \multirow{2}{*}{0.628} \\
\hline Groups B & 12 & 8 & 6 & 26 & \\
\hline Total & 28 & 14 & 11 & 53 & \\
\hline
\end{tabular}

Abbreviation: CFU, colony-forming unit.

Intervention in periodontal therapy nowadays includes host modulatory therapies that are being used as adjuvant conventional therapy. Researchers are continuously hunting for new host modulating agent which can be used in periodontal therapy.
RSV is potent anti-inflammatory, ${ }^{23}$ stimulates osteoblastic differentiation, ${ }^{24}$ and can be used as host modulating as well as bone anabolic agent in the treatment of chronic periodontitis. Author in the present study is focusing on anti-inflammatory, regenerative potential and antimicrobial efficacy of RSV.

The study showed significant reduction in mean PD in group A compared to group B and significant gain in CAL in group A compared to group $B$. There is a significant bone fill in group $A$ and decrease in bone defect depth. The bone fill is due to statins act on mevalonate pathway in osteoblast and by increasing the expression of growth factor BMP-2causes osteoblastic differentiation and bone formation. ${ }^{25,26}$ In an in vivo animal study when statin was injected locally over calvaria bone of mice cause 30 to $50 \%$ increase in calvarial width. Bone formation by this drug is stimulated by inhibition of prenylation. ${ }^{10}$ In addition to the above, by regulating estrogen receptors, osteoprotegerin-receptor activator of nuclear factor kappa B (NF-KB)/receptor activator of NF-KB ligand inhibits osteoclastogenesis and promotes osteoblastic differentiation and hence osteostimulative effect. ${ }^{27}$ In a similar study by Pradeep et al, RSV in situ gel (1.2\%), when delivered locally into IBD/pocket sites, showed a greater reduction than placebo with respect to PD and gingival index, along with increased gain in CAL. ${ }^{28}$ The bone fill is due to RSV which possesses osteoblast differentiation. The limitation of above study is that it employs conventional intraoral periapical radiograph for radiographic analysis. The two-dimensional (2D) IBD analyses are limited to projection geometry.

However, in the present study, CBCT was used for the analysis of IBD. CBCT displays 2D and 3D images that are required for diagnosis and treatment plan of IBD. Alamri et al confirmed that due to projection errors $2 \mathrm{D}$ radiographs are inadequate for detecting changes at the bone level especially in the furcation and buccal and lingual aspect. CBCT provides accurate measurements of IBD. CBCT also allows the clinician to evaluate the postsurgical follow-up results of regenerative periodontal therapy. ${ }^{29}$

In the present study, there has been no significant difference in PI and bleeding index on intergroup comparison. However, within the groups, there is a significant decrease in PI and bleeding index ( - Tables 4 and $\mathbf{5}$ ). Bleeding on probing is a clinical parameter with low-positive predictive value and high-negative predictive value on absent. That is absence of bleeding suggests periodontal stability. ${ }^{30}$ There is no difference in bleeding index in both the groups, which suggest that the plaque control could be similar in both groups. Plaque score is an indicator of patient compliance, as patients in the study demonstrated similar daily plaque control procedures. This could be reason for similar reduction in PI and bleeding index within both groups. ${ }^{31}$

RSV has shown pleiotropic antimicrobial effect. In an in vitro study, RSV has antimicrobial shown against Pseudomonas aeruginosa (ATCC 9027) (Gram-negative, facultative anaerobic, Staphylococcus aureus (ATCC 6538). ${ }^{32}$ Similarly, in another in vitro study, RSV has shown antimicrobial effect against methicillin-susceptible S. aureus. ${ }^{33}$ Based on the above literature, antimicrobial efficacy was evaluated. To the best of 
our knowledge, the present study is the first study to check the antimicrobial effect of RSV on periodontal pathogens.

Although mechanical debridement substantially reduces the number of periodontal pathogens, recolonization with pathogenic species starts immediately after mechanical therapy. ${ }^{13}$ Thus, the hypothesis is locally delivered RSV could retard the recolonization. There is no significant difference in the anaerobic $\mathrm{CFU} / \mathrm{mL}$, in both the groups after 180 days (Tables 3). This could be due to the fact that the anaerobic analysis was done on smaller sample size, that is, 32 subjects per group. Further, longitudinal study with larger sample size and different concentration of RSV is required to check the antimicrobial effect of RSV.

The results of the present study confirm that when $1.2 \%$ RSV gel locally delivered into subgingival area promoted bone fill in IBD, reduction in PD, and CAL gain. The result of the study is in concordance with various studies showing improved periodontal parameters when various statins delivered locally. ${ }^{34}$ In another study, RSV showed better improvement in clinical and radiographic periodontal parameters than other statin atorvastatin and simvastatin. ${ }^{35}$

RSV can evolve as new economical host modulating agent in periodontal therapy as it possesses anti-inflammatory, antioxidant, and immune modulatory properties. Studies have shown RSV reduces the expression of cytokines, such as interleukin (IL)-6, IL-1 $\alpha$, IL-1 $\beta$, and tumor necrosis factor in ligature-induced periodontitis in rat model. ${ }^{36}$

The local route of administration of RSV has two main advantages: first when orally administered there bioavailability is low because of their high-liver specificity ${ }^{37}$ second when delivered through sustained release system, reaches the desired target area, slows the progression of disease, and shows significant bone formation, even when administered in low concentration..$^{38}$ Hence, locally delivered RSV can emerge as host modulating therapy adjunct to mechanical therapy.

\section{Conclusion}

An increased knowledge of host immune inflammatory mediators in chronic periodontitis has increased the number of researches in host modulatory agents used as an adjunct therapy to periodontal therapy. The study concludes that locally administered $1.2 \%$ RSV has bone anabolic and anti-inflammatory effect and can emerge as a host modulatory agent. Further, randomized clinical controlled trials are required to evaluate the antimicrobial and clinical efficacy of $\mathrm{RSV}$ at different concentration to support the finding of the present study.

\section{Financial Support and Sponsorship \\ Nil.}

\section{Conflicts of Interest}

None declared.

\section{References}

1 Slots J. Periodontology: past, present, perspectives. Periodontol 2000 2013;62(1):7-19

2 Shimizu H, Nakagami H, Morita S, et al. New treatment of periodontal diseases by using NF-kappaB decoy oligodeoxynucleotides via prevention of bone resorption and promotion of wound healing. Antioxid Redox Signal 2009;11(9):2065-2075

3 Haffajee AD, Socransky SS. Microbial etiological agents of destructive periodontal diseases. Periodontol 2000 1994;5:78-111

4 Seymour GJ. Importance of the host response in the periodontium. J Clin Periodontol 1991;18(6):421-426

5 Pihlstrom BL. Periodontal risk assessment, diagnosis and treatment planning. Periodontol 2000 2001;25:37-58

6 Vandekerckhove BN, Quirynen M, van Steenberghe D. The use of locally delivered minocycline in the treatment of chronic periodontitis. A review of the literature. J Clin Periodontol 1998;25(11 Pt 2):964-968, discussion 978-979

7 Pandit N, Dahiya R, Gupta R, Bali D, Kathuria A. Comparative evaluation of locally delivered minocycline and metronidazole in the treatment of periodontitis. Contemp Clin Dent 2013;4(1):48-53

8 Da Rocha HA, Silva CF, Santiago FL, Martins LG, Dias PC, De Magalhães D. Local drug delivery systems in the treatment of periodontitis: a literature review. J Int Acad Periodontol 2015;17(3):82-90

9 Evans M, Roberts A, Davies S, Rees A. Medical lipid-regulating therapy: current evidence, ongoing trials and future developments. Drugs 2004;64(11):1181-1196

10 Garrett IR, Mundy GR. The role of statins as potential targets for bone formation. Arthritis Res 2002;4(4):237-240

11 Resch U, Tatzber F, Budinsky A, Sinzinger H. Reduction of oxidative stress and modulation of autoantibodies against modified low-density lipoprotein after rosuvastatin therapy. Br J Clin Pharmacol 2006;61(3):262-274

12 Willerson JT, Ridker PM. Inflammation as a cardiovascular risk factor. Circulation 2004;109(21, Suppl 1):II2-II10

13 Jerwood S, Cohen J. Unexpected antimicrobial effect of statins. J Antimicrob Chemother 2008;61(2):362-364

14 Monjo M, Rubert M, Ellingsen JE, Lyngstadaas SP. Rosuvastatin promotes osteoblast differentiation and regulates SLCO1A1 transporter gene expression in MC3T3-E1 cells. Cell Physiol Biochem 2010;26(4-5):647-656

15 Maeda T, Matsunuma A, Kurahashi I, Yanagawa T, Yoshida H, Horiuchi N. Induction of osteoblast differentiation indices by statins in MC3T3-E1 cells. J Cell Biochem 2004;92(3):458-471

16 Jordan E, Hsu YT, Bashutski J. Do statin medications improve periodontal health and/or outcomes? A systematic review. Clinic Adv Periodontics 2014;4(3):194-202

17 Muniz FWMG, Taminski K, Cavagni J, Celeste RK, Weidlich P, Rösing CK. The effect of statins on periodontal treatment-a systematic review with meta-analyses and meta-regression. Clin Oral Investig 2018;22(2):671-687

18 Deas DE, Moritz AJ, Sagun RS Jr, Gruwell SF, Powell CA. Scaling and root planing vs. conservative surgery in the treatment of chronic periodontitis. Periodontol 2000 2016;71(1):128-139

19 Silness J, Loe H. Periodontal disease in pregnancy. II. Correlation between oral hygiene and periodontal condtion. Acta Odontol Scand 1964;22:121-135

20 El-Makaky YM. Clinical and radiographical evaluation of osseointegration around immediate endosseous implant using fresh-frozen bone allograft. J Am Sci 2013;9:90-97

21 Final report on the safety assessment of hydroxyethyl cellulose, hydroxypropyl cellulose, methylcellulose, hydroxypropyl methylcellulose and cellulose gum. Int J Toxicol 1986;5:1-59 
22 Amano A. Host-parasite interactions in periodontitis: microbial pathogenicity and innate immunity. Periodontol 2000 2010;54(1):9-14

23 Tandon V, Bano G, Khajuria V, Parihar A, Gupta S. Pleiotropic effects of statins. Indian J Pharmacol 2005;37(2):77-85

24 Tobert JA. New developments in lipid-lowering therapy: the role of inhibitors of hydroxymethylglutaryl-coenzyme A reductase. Circulation 1987;76(3):534-538

25 Ghosh-Choudhury N, Mandal CC, Choudhury GG. Statininduced Ras activation integrates the phosphatidylinositol 3-kinase signal to Akt and MAPK for bone morphogenetic protein-2 expression in osteoblast differentiation. J Biol Chem 2007;282(7):4983-4993

26 Maeda T, Matsunuma A, Kawane T, Horiuchi N. Simvastatin promotes osteoblast differentiation and mineralization in MC3T3-E1 cells. Biochem Biophys Res Commun 2001;280 (3):874-877

27 Landmesser U, Bahlmann F, Mueller M, et al. Simvastatin versus ezetimibe: pleiotropic and lipid-lowering effects on endothelial function in humans. Circulation 2005;111(18):2356-2363

28 Pradeep AR, Karvekar S, Nagpal K, Patnaik K, Guruprasad CN, Kumaraswamy KM. Efficacy of locally delivered $1.2 \%$ rosuvastatin gel to non-surgical treatment of patients with chronic periodontitis: a randomized, placebo-controlled clinical trial. J Periodontol 2015;86(6):738-745

29 Kumar M, Shanavas M, Sidappa A, Kiran M. Cone beam computed tomography - know its secrets. J Int Oral Health 2015;7(2):64-68

30 Joss A, Adler R, Lang NP. Bleeding on probing. A parameter for monitoring periodontal conditions in clinical practice. J Clin Periodontol 1994;21(6):402-408
31 Lang NP, Joss A, Orsanic T, Gusberti FA, Siegrist BE. Bleeding on probing. A predictor for the progression of periodontal disease? J Clin Periodontol 1986;13(6):590-596

32 Alagić-Džambić L, Omerović S, Džambić M. Antimicrobial activity of rosuvastatin. Int J Pharm Tech 2015;6(4):7587-7592

33 Tekce M, Ince G, Gursoy $\mathrm{H}$, et al. Clinical and microbiological effects of probiotic lozenges in the treatment of chronic periodontitis: a 1-year follow-up study. J Clin Periodontol 2015;42(4):363-372

34 Fajardo ME, Rocha ML, Sánchez-Marin FJ, Espinosa-Chávez EJ. Effect of atorvastatin on chronic periodontitis: a randomized pilot study. J Clin Periodontol 2010;37(11):1016-1022

35 Pradeep AR, Garg V, Kanoriya D, Singhal S. 1.2\% rosuvastatin versus $1.2 \%$ atorvastatin gel local drug delivery and redelivery in treatment of intrabony defects in chronic periodontitis: a randomized placebo-controlled clinical trial. J Periodontol 2016;87(7):756-762

36 Messora MR, Apolinário Vieira GH, Vanderlei JMTMM, et al. Rosuvastatin promotes benefits on induced periodontitis in hypertensive rats. J Periodontal Res 2017;52(4):734-744

37 Monjo M, Rubert M, Wohlfahrt JC, Rønold HJ, Ellingsen JE, Lyngstadaas SP. In vivo performance of absorbable collagen sponges with rosuvastatin in critical-size cortical bone defects. Acta Biomater 2010;6(4):1405-1412

38 Pradeep AR, Thorat MS. Clinical effect of subgingivally delivered simvastatin in the treatment of patients with chronic periodontitis: a randomized clinical trial. J Periodontol 2010;81(2):214-222 